\title{
The impact of obesity on hyperandrogenemia in Korean girls
}

\author{
Min Jae Kang, $\mathrm{MD}^{1, *}$, \\ Seung Yang, $\mathrm{MD}^{2, *}$, \\ II Tae Hwang, MD²
}

${ }^{1}$ Department of Pediatrics, Hallym University Sacred Heart Hospital, Anyang-si, ${ }^{2}$ Department of Pediatrics, Kangdong Sacred Heart Hospital, Seoul, Korea
Received: 15 October, 2016

Revised: 7 December, 2016

Accepted: 9 December, 2016

Address for correspondence:

II Tae Hwang, MD, PhD

Department of Pediatrics, Hallym

University Kangdong Sacred Heart

Hospital, 150 Seongan-ro, Gangdong-

gu, Seoul 05355, Korea

Tel: +82-2-2224-2251

Fax: +82-2-482-8334

E-mail: ithwang83@hallym.or.kr http://orcid.org/0000-0002-38854322

\footnotetext{
*These authors contributed equally to this study and should be considered co-first authors.
}

Purpose: As metabolic complication and polycystic ovarian syndrome due to childhood obesity is rising, the role of hyperandrogenemia (HA) and hyperinsulinism is receiving attention. The aims of this study were to investigate the presence of obvious $\mathrm{HA}$ according to pubertal status and to find potential etiologic determinants of HA in Korean obese (OB) girls.

Methods: We analyzed 91 girls aged $6-17$ years (prepuberty, $n=54$; puberty, $n=37$ ). Each girl was classified as being either normal weight (NW) or OB. Anthropometric measurements were obtained and blood test was performed early in the morning after at least 8 hours of fasting to measure glucose, insulin, total testosterone, sex hormone-binding globulin, dehydroepiandrosterone sulfate (DHEAS), luteinizing hormone (LH), follicular-stimulating hormone, estradiol, and progesterone.

Results: The plasma levels of free testosterone (FT) and DHEAS were markedly higher in OB girls compared to NW girls in puberty ( $F T, P=0.009$; DHEAS, $P=0.046$ ) but not in prepuberty ( $F T, P=0.183$; DHEAS, $P=0.052$ ). Hyperinsulinemia and high homeostasis model assessment of insulin resistance (HOMA-IR) values were found regardless of pubertal status in $\mathrm{OB}$ girls. The significant related factor to $\mathrm{HA}$ in puberty was the body mass index $Z$-score $(P=0.003)$. But HOMA-IR, LH, and progesterone levels were not relevant to $\mathrm{HA}$ in pubertal girls.

Conclusion: $\mathrm{OB}$ prepubertal girls did not show HA in the present study but they should be regularly monitored because they already had hyperinsulinemia. OB pubertal girls had significant $\mathrm{HA}$ and hyperinsulinemia, and obesity per se was the most important factor for $\mathrm{HA}$.

Keywords: Obesity, Hyperandrogenemia, Korean

\section{Introduction}

Childhood obesity has increased all over the world in the past decades and Korea is no exception ${ }^{1)}$. As the impact of childhood obesity on adulthood metabolic complications is considered important ${ }^{2}$, the polycystic ovarian syndrome (PCOS), which is a reproductive complication $^{3)}$, is also receiving attention. PCOS, a disorder of ovarian dysfunction, is characterized by relatively high androgen concentrations, metabolic abnormalities and many other conditions of the metabolic syndrome $e^{4)}$. Because PCOS patients may enter the hyperandrogenism-hyperinsulinism cycle, there is no doubt that obesity plays a significant role $^{5}$. There are many efforts to reveal the definite interacting mechanisms between obesity, hyperinsulinemia, hyperandrogenemia (HA), and gonadotropins ${ }^{4,6,7)}$. Hyperandrogenism, which was selected as one of the critical criteria for PCOS by Androgen Excess Society in $2006^{8}$, was reported as a significant risk factor for metabolic syndrome in PCOS patients ${ }^{97}$.

Clinical manifestations of PCOS may develop even in adolescence ${ }^{3)}$, often begin during or soon after puberty. And HA during early adolescence may represent a precursor of adult $\mathrm{PCOS}^{10)}$, thus, early pubertal obesity and HA should not be overlooked. Recent insights suggest 
that peripubertal obesity was associated with marked HA, which was pronounced in prepuberty and early puberty ${ }^{11,12)}$. However, other studies reported that not all obese (OB) girls have HA and some of early pubertal OB girls had normal androgen concentrations ${ }^{13,14)}$. Therefore, the presence of HA and its role in childhood and adolescence is not clear to date.

There have been proposed various preceding factors of HA. Increased fat compartment is a well-known factor ${ }^{15}$. Weight loss induced a decrease in testosterone levels in $\mathrm{OB}$ prepubertal and pubertal girls, pointing to HA as a reversible phenomenon ${ }^{16)}$. But obesity per se is not sufficient to produce $\mathrm{HA}^{14)}$. Luteinizing hormone (LH), which is a major physiological stimulus for ovarian androgen production from theca cells, is related to $\mathrm{HA}^{6}$. And hyperinsulinemia contributes to HA through several mechanisms ${ }^{17-19)}$ including potentiation of LH action.

To our knowledge, this is the first study of HA in OB Korea girls including prepubertal age. The prevalence of morbid obesity is relatively low in Korea compared to the Western Countries $^{20)}$ and metabolic consequences according to the same body mass index (BMI) are different among ethnic groups. Therefore, we aimed to investigate the presence of obvious HA and to find potential etiologic determinants of HA in both prepubertal and pubertal Korean OB girls

\section{Materials and methods}

\section{Subjects}

Between June 2007 and May 2008, 99 girls aged 6-17 years who visited the Hallym Medical Center outpatient clinics due to their health check-ups were enrolled retrospectively. All participants and their ancestors were Korean. Anthropometric measurements were obtained from each subject. Height was measured twice to the first decimal place with a Harpenden stadiometer (Holtain Ltd., Crosswell, UK) and weight to the first decimal place with a digital scale (150A, Cas Co. Ltd., Seoul, Korea). To calculate BMI, weight was divided by the square of the height $\left(\mathrm{kg} / \mathrm{m}^{2}\right)$. With the measured height and weight, BMI Z-scores were obtained by using Korean growth standard published by the Korea Centers for Disease Control and Prevention ${ }^{21)}$. Each girl was classified as being either normal weight (NW) (BMI adjusted for age between 5th-84th percentile) or OB (BMI adjusted for age $\geq 95$ th percentile). Waist and hip circumferences were measured at a horizontal level 1 inch above the navel and around the widest portion of the buttocks, respectively. Waist to hip ratio (WHR) was also calculated. Tanner stage was evaluated by a single female pediatric endocrinologist who conducted both inspection and palpation of breasts. Subjects were assigned to prepuberty (Tanner breast stage I) or puberty (Tanner breast stage IV-V). Exclusion criteria were as follows: underweight, BMI adjusted for age below 5th percentile; overweight, BMI adjusted for age between 85 th-94th percentile; Tanner breast stage II-III. All subjects had a blood test early in the morning after at least 8 hours of fasting. All subjects had taken no medications known to affect the reproductive axis for at least 3 months before the study. This study protocol was approved by the Institutional Review Board of Hallym Medical Center (KANGDONG 201608-002).

After study enrollment, 8 subjects were excluded as follows: one subject whose fasting plasma glucose level was $295 \mathrm{mg} /$ $\mathrm{dL}$; and 7 subjects with a morning progesterone concentration greater than $2 \mathrm{ng} / \mathrm{mL}$ in Tanner stage IV-V, which sampling is during the luteal phase ${ }^{14)}$. Therefore, 91 subjects were included in this study and the number of subjects in NW prepuberty, $\mathrm{OB}$ prepuberty, NW puberty, and OB puberty group was $24,30,11$, and 26, respectively. Because there was 12 missing data in waist or hip circumferences, WHR was calculated in 79 subjects.

\section{Hormone assays}

Glucose was measured by enzymatic reference method with hexokinase (Roche Diagnostics, Indianapolis, IN, USA): sensitivity, $2 \mathrm{mg} / \mathrm{dL}$. Insulin, progesterone, and sex hormone-binding globulin (SHBG) were measured by electrochemiluminescence immunoassay (Roche Diagnostics, Indianapolis, IN, USA). LH and follicular-stimulating hormone (FSH) were measured by IRMA (Siemens Medical Solutions Diagnostics, Los Angeles, CA, USA). Total testosterone (TT), dehydroepiandrosterone sulfate (DHEAS), and estradiol were measured by RIA (Siemens Medical Solutions Diagnostics, Los Angeles, CA, USA). Sensitivity, interassay and intra-assay coefficients of variation for each hormone were as follows: insulin, $0.1 \mu \mathrm{U} / \mathrm{mL}, 2.5 \%-2.8 \%$, and $1.9 \%-2.0 \%$; progesterone, $0.03 \mathrm{ng} / \mathrm{mL}, 4.1 \%-5.5 \%$, and $1.5 \%-2.7 \%$; SHBG, $0.35 \mathrm{nmol} /$ L, $1.8 \%-4.0 \%$, and $2.7 \%-5.6 \%$; LH, $0.1 \mathrm{IU} / \mathrm{L}, 3.2-4.1$, and 5.3\%-6.6\%; FSH, 0.05 IU/L, 2.2\%-2.3\%, and 5.9\%-6.3\%; TT, 0.1 $\mathrm{ng} / \mathrm{mL}, 7.8 \%-9.3 \%$, and 1.5\%-6.1\%; DHEAS, $0.1 \mu \mathrm{g} / \mathrm{dL}, 3.4 \%-$ $10.6 \%$, and $3.5 \%-7.4 \%$; and estradiol, $0.1 \mathrm{pg} / \mathrm{mL}, 4.2 \%-8.1 \%$, and $4.0 \%-7.0 \%$.

Free testosterone (FT) was calculated from TT and SHBG using the following equation ${ }^{22)}: \mathrm{FT}=[\mathrm{TT}-(\mathrm{N})(\mathrm{FT})] /\left[\left(\mathrm{K}_{\mathrm{T}}\right)\right.$ $\left.(\mathrm{SHBG})-\left(\mathrm{K}_{\mathrm{T}}\right)(\mathrm{TT})+(\mathrm{N})\left(\mathrm{K}_{\mathrm{T}}\right)(\mathrm{FT})\right]$. In this equation, $\mathrm{FT}$ is free testosterone concentration $(\mathrm{pmol} / \mathrm{L})$; TT is total testosterone concentration (nmol/L); SHBG is SHBG concentration (nmol/ $\mathrm{L}$ ); $\mathrm{KT}$ is the association constant of SHBG for testosterone $\left(1.0 \times 10^{9} \mathrm{~L} / \mathrm{mol}\right) ; \mathrm{N}=\left(\mathrm{K}_{\mathrm{A}}\right)\left(\mathrm{C}_{\mathrm{A}}\right)+1$, where $\mathrm{KA}$ is the association constant of albumin for testosterone $\left(3.6 \times 10^{4} \mathrm{~L} / \mathrm{mol}\right)$, and CA is the albumin concentration $(\fallingdotseq 4.3 \mathrm{~g} / \mathrm{dL})$. Homeostasis model assessment of insulin resistance (HOMA-IR) was calculated from fasting plasma glucose and insulin using the equation as follows: HOMA-IR=Glucose $(\mathrm{mg} / \mathrm{dL}) \times$ insulin $(\mu \mathrm{IU} / \mathrm{mL}) / 405^{23)}$.

\section{Statistics}

All data were presented as median and interquartile ranges. Mann-Whitney $U$-test or chi-square test was used to examine differences between the 2 groups, classified according to 
BMI and Tanner stage. Spearman correlation coefficient was calculated to test the association between 2 continuous parameters. All hormone variables were highly skewed and logarithmic transformation was performed before multivariate regression analysis which was used to determine factors related to $\mathrm{HA}$ after controlling for other variables. $P$-values $<0.05$ were considered significant. All statistical analyses were performed using IBM SPSS Statistics ver. 21.0 (IBM Co., Armonk, NY, USA).

\section{Results}

\section{Clinical characteristics of subjects and insulin related indices}

Clinical characteristics and hormone results of each group are presented in Table 1. Height $Z$-score of OB subjects was higher than that of NW subjects in both prepuberty and puberty. Birth weight of OB subjects was heavier than that of NW subjects in both prepuberty and puberty but all data was within normal range (median birth weight; NW prepuberty, $3.2 \mathrm{~kg}$; OB prepuberty $3.4 \mathrm{~kg}$; NW puberty, $2.5 \mathrm{~kg}$; OB puberty, $3.3 \mathrm{~kg}$ ). In total subjects, WHR showed positive correlation with BMI $Z$-score $(r=0.421, P<0.001, \mathrm{n}=79)$, fasting insulin level $(r=0.244$, $P=0.030, \mathrm{n}=79)$, and HOMA-IR $(r=0.232, P=0.040, \mathrm{n}=79)$. In prepuberty group, WHR showed good correlation with BMI $Z$-score $(r=0.501, P<0.001, \mathrm{n}=45)$, fasting insulin level $(r=0.456$, $P=0.002, \mathrm{n}=45)$, and HOMA-IR $(r=0.438, P=0.003, \mathrm{n}=45)$ but when considering for age, BMI Z-score, and HOMA-IR or insulin level all together, only BMI $Z$-score showed significance

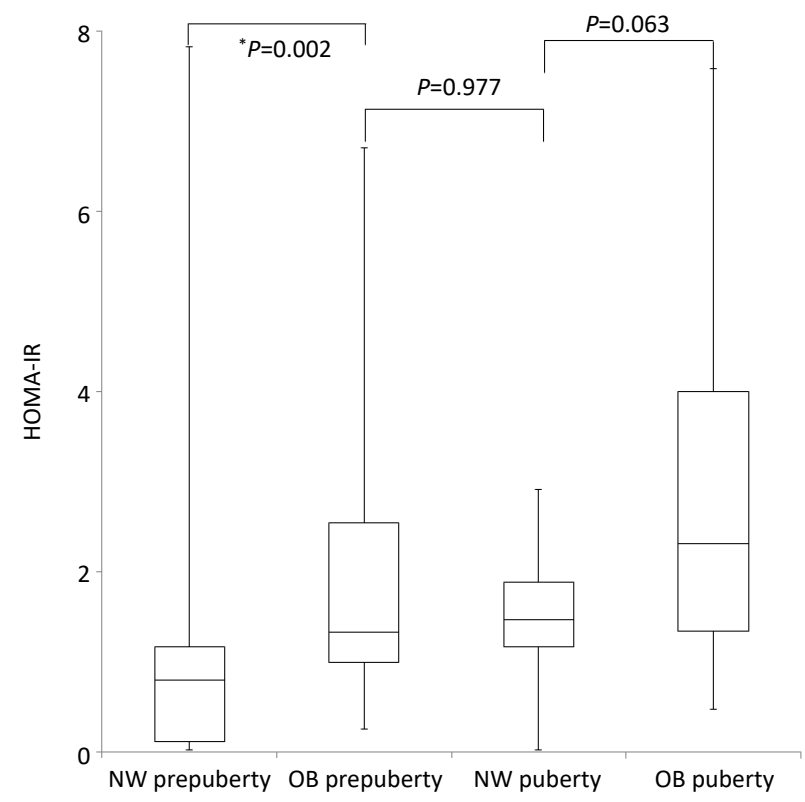

Fig. 1. Box plots of homeostasis model assessment of insulin resistance (HOMAIR) values of each group are shown. Obese (OB) subjects had higher HOMA-IR values than normal weight (NW) subjects in prepuberty $(P=0.002)$. But in puberty those differences were marginally significant $(P=0.063)$. HOMA-IR values of $O B$ prepuberty group showed similar levels compared to those of NW puberty group $(P=0.977) .{ }^{*} P<0.05$

Table 1. Clinical characteristics and hormone results in subjects

\begin{tabular}{|c|c|c|c|c|}
\hline \multirow{2}{*}{ Characteristic } & \multicolumn{2}{|c|}{ Prepuberty } & \multicolumn{2}{|c|}{ Puberty } \\
\hline & NW $(n=24)$ & $\mathrm{OB}(\mathrm{n}=30)$ & NW $(n=11)$ & $O B(n=26)$ \\
\hline Age $(y r)^{c, d, e)}$ & $8.3(7.3-8.8)$ & $8.3(7.8-9.0)$ & $13.8(11.7-15.1)$ & $14.4(12.9-14.9)$ \\
\hline Height Z-score ${ }^{a, b, c, e)}$ & $0.26(-0.34-0.70)$ & $1.36(0.86-1.62)$ & $-0.56(-1.14-0.28)$ & $0.74(0.26-1.56)$ \\
\hline Weight Z-score ${ }^{a, b, e)}$ & $0.10(-0.52-0.73)$ & $2.07(1.73-2.36)$ & $-0.30(-0.90-0.11)$ & $2.22(1.95-2.66)$ \\
\hline BMI Z-score ${ }^{a, b, e)}$ & $0.18(-0.60-0.59)$ & $2.07(1.84-2.30)$ & $-0.21(-0.68-0.62)$ & $2.08(1.85-2.37)$ \\
\hline$W H R^{a, e)}$ & $0.82(0.78-0.87)$ & $0.90(0.86-0.92)$ & $0.82(0.79-0.85)$ & $0.85(0.81-0.92)$ \\
\hline Glucose (mg/dL) & $96(90-105)$ & 97 (89-101) & $99(95-110)$ & $95(91-101)$ \\
\hline Insulin $(\mu \mid \bigcup / m L)^{a, b, c)}$ & $3.4(0.3-4.8)$ & $5.6(3.9-10.9)$ & $6.6(4.3-7.1)$ & $9.8(4.7-16.0)$ \\
\hline HOMA-IR ${ }^{a, c)}$ & $0.79(0.06-1.19)$ & $1.34(0.96-2.58)$ & $1.47(1.01-1.97)$ & $2.31(1.24-4.08)$ \\
\hline DHEAS $(\mu \mathrm{g} / \mathrm{dL})^{\mathrm{c}, \mathrm{d})}$ & $39.1(15.1-88.1)$ & $73.1(27.1-131.9)$ & $99.3(86.4-140.5)$ & $150.7(113.1-193.6)$ \\
\hline $\mathrm{TT}(\mathrm{ng} / \mathrm{mL})^{\mathrm{b}, \mathrm{c}, \mathrm{d}, \mathrm{e})}$ & $0.10(0.10-0.10)$ & $0.10(0.10-0.10)$ & $0.20(0.10-0.27)$ & $0.31(0.20-0.47)$ \\
\hline $\mathrm{FT}(\mathrm{pmol} / \mathrm{L})^{\mathrm{b}, \mathrm{c}, \mathrm{d}, \mathrm{e})}$ & $3.4(2.4-4.9)$ & $4.1(3.2-5.3)$ & $8.6(5.5-13.8)$ & $14.5(8.8-29.2)$ \\
\hline SHBG $(n m o l / L)^{d)}$ & $78.6(51.8-120.6)$ & $60.3(40.6-84.1)$ & $51.3(39.9-89.9)$ & $37.0(28.6-58.0)$ \\
\hline$L H(I U / L)^{c, d, e)}$ & $0.1(0.1-0.1)$ & $0.1(0.1-0.1)$ & $4.3(2.3-4.7)$ & $4.0(1.7-9.1)$ \\
\hline FSH $(I U / L)^{c, d, e)}$ & $1.8(0.3-2.8)$ & $1.7(0.9-2.2)$ & $4.3(3.0-6.0)$ & $4.7(4.0-6.1)$ \\
\hline LH:FSH ratio ${ }^{c, d, e)}$ & $0.06(0.04-0.78)$ & $0.06(0.05-0.14)$ & $1.00(0.61-1.33)$ & $0.77(0.31-1.71)$ \\
\hline Estradiol $(\mathrm{pg} / \mathrm{mL})^{\mathrm{c}, \mathrm{d})}$ & $0.1(0.1-0.1)$ & $0.1(0.1-2.5)$ & $0.3(0.1-32.2)$ & $28.9(11.5-41.5)$ \\
\hline Progesterone $(\mathrm{ng} / \mathrm{mL})^{\mathrm{c}, \mathrm{d}, \mathrm{e})}$ & $0.4(0.2-0.6)$ & $0.3(0.2-0.6)$ & $0.6(0.4-1.1)$ & $0.7(0.4-1.1)$ \\
\hline
\end{tabular}

Values are presented as median (interquartile range).

NW, normal weight; OB, obese; BMI, Body mass index; WHR, Waist to hip ratio; HOMA-IR, Homeostatic model assessment of insulin resistance; DHEAS, dehydroepiandrosterone sulfate; TT, total testosterone; FT, free testosterone; SHBG, sex hormone-binding globulin; LH, luteinizing hormone; FSH, Follicle-stimulating hormone.

a) $P<0.05$, NW prepubertal girls vs. OB prepubertal girls. ${ }^{\text {b) }} P<0.05$, NW pubertal girls vs. OB pubertal girls. ${ }^{\text {c) }} P<0.05$, NW prepubertal girls vs. NW pubertal girls. ${ }^{d)} P<0.05$, OB prepubertal girls vs. OB pubertal girls. ${ }^{e)} P<0.05$, OB prepubertal girls vs. NW pubertal girls. 
$(P=0.006)$. In puberty group, WHR and BMI $Z$-score showed positive correlation with marginal significance $(r=0.322$, $P=0.063, \mathrm{n}=34$ ) and it was not valid after controlling for age, and HOMA-IR or insulin.

Plasma glucose level was not different among the 4 groups. In all 91 subjects, HOMA-IR was correlated with age and BMI $Z$-score (adjusted $R^{2}=0.313$; age, $\beta=0.039, P=0.030$; $B M I Z$-score, age, $B=0.252, P<0.001)$. OB subjects had higher HOMAIR values than NW subjects in prepuberty $(P=0.002)$. But in puberty those differences were marginally significant $(P=0.063)$. Plasma insulin level and HOMA-IR showed no differences between $\mathrm{OB}$ prepuberty group and NW puberty group (insulin, $P=0.825$; HOMA-IR, $P=0.977$ ) (Table 1, Fig. 1).

\section{Androgen and gonadotropic hormone profiles}

In puberty, plasma FT levels of $\mathrm{OB}$ subjects were about 2 times higher than those of NW subjects $(P=0.018)$ (Fig. 2), while those were similar between $\mathrm{OB}$ and NW subjects in prepuberty $(P=0.127)$. Plasma levels of TT and FT were higher in NW puberty group than in $\mathrm{OB}$ prepuberty group (both $P<0.001$ ). When age, log HOMA-IR, log LH and log progesterone were considered together in the multiple regression analysis, BMI $Z$-score and log progesterone showed significant correlation with the increased log FT in pubertal girls (Table 2). In prepuberty, TT and FT levels were randomly distributed regardless of age, BMI $Z$-score, and other variables. SHBG showed negative correlation with BMI $Z$-score $(r=-0.330, P=0.001)$ but there were no differences between $\mathrm{OB}$ and NW subjects in both prepuberty and puberty (Table 1).

In puberty, DHEAS levels showed patterns similar to FT levels but their differences between $\mathrm{OB}$ and NW subjects were marginally significant $(P=0.060)$. In the multiple regression analysis, DHEAS levels of pubertal girls had significant correlations with BMI Z-score and plasma levels of LH and progesterone (Table 2). In prepuberty, DHEAS levels were not different between $\mathrm{OB}$ and NW subjects $(P=0.180)$. There were no differences between $\mathrm{OB}$ prepuberty group and NW puberty $\operatorname{group}(P=0.131)$

In total 91 subjects, plasma levels of $\mathrm{LH}, \mathrm{FSH}, \mathrm{LH}$ to FSH ratio, and progesterone were not associated with the BMI $Z$-score, while their differences were only affected by pubertal status.
Within puberty subjects, plasma LH level was not correlated with BMI $Z$-score $(r=-0.089, P=0.599, \mathrm{n}=37)$ or HOMAIR values $(r=0.053, P=0.755, \mathrm{n}=37)$ in the simple correlation analysis.

\section{Discussion}

In our study, hyperinsulinemia and high HOMA-IR values in OB subjects were confirmed regardless of pubertal status although they showed marginal significance in pubertal girls. But marked HA was found in OB girls compared to NW girls only after puberty. And significant factors related to HA was the BMI Z-score and progesterone levels, while, HOMA-IR and LH levels were not relevant to HA. In prepuberty, against our expectation, there was no evidence of $\mathrm{HA}$ in $\mathrm{OB}$ subjects despite they had higher HOMA-IR and insulin levels than NW subjects.

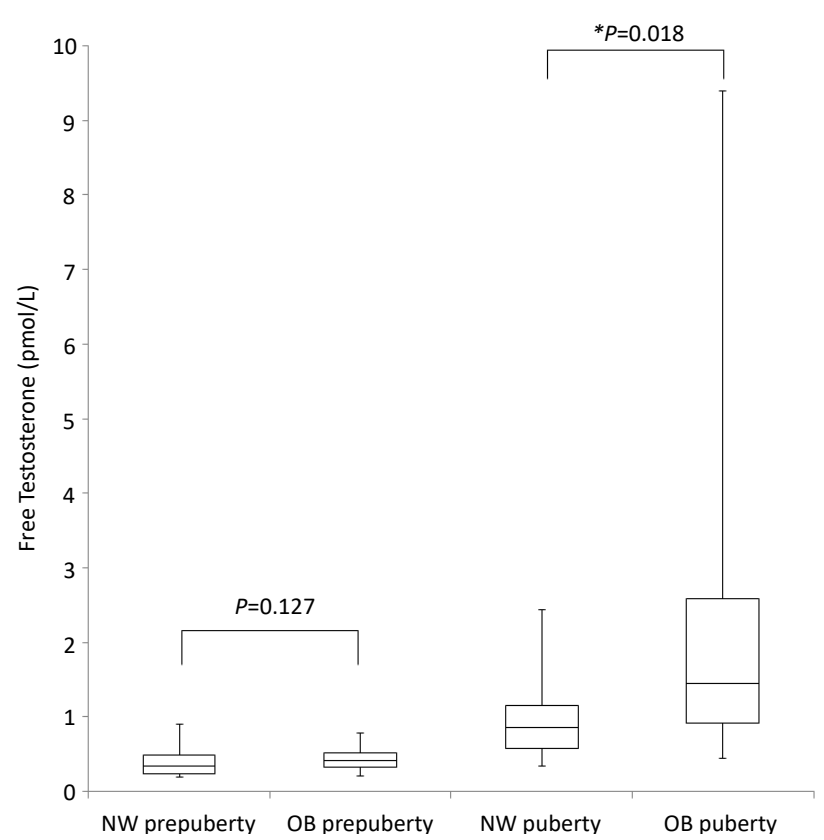

Fig. 2. Box plots of free testosterone levels of each group are shown. In prepuberty, free testosterone levels were similar between obese (OB) and normal weight (NW) groups $(P=0.127)$, while in puberty, it was about 2 times higher in OB groups than in NW groups $(P=0.018)$. ${ }^{*} P<0.05$

Table 2. Multiple regression model of plasma levels of free testosterone and dehydroepiandrosterone sulfate in puberty subjects

\begin{tabular}{|c|c|c|c|c|c|c|}
\hline \multirow{2}{*}{ Variable } & \multicolumn{3}{|c|}{ Log FT } & \multicolumn{3}{|c|}{ Log DHEAS } \\
\hline & Coefficient & SE & $P$-value & Coefficient & SE & $P$-value \\
\hline Age & -0.006 & 0.031 & 0.861 & 0.028 & 0.030 & 0.372 \\
\hline BMI Z-score & 0.136 & 0.040 & 0.002 & 0.122 & 0.038 & 0.003 \\
\hline Log HOMA-IR & 0.144 & 0.102 & 0.166 & -0.155 & 0.099 & 0.125 \\
\hline $\log \mathrm{LH}$ & 0.132 & 0.080 & 0.110 & 0.193 & 0.078 & 0.019 \\
\hline Log progesterone & 0.517 & 0.160 & 0.003 & 0.379 & 0.156 & 0.021 \\
\hline
\end{tabular}

FT, free testosterone; DHEAS, dehydroepiandrosterone sulfate; BMI, body mass index; HOMA-IR, homeostasis model assessment of insulin resistance; $L \mathrm{H}$, luteinizing hormone.

Log FT, adjusted $R^{2}=0.513, P<0.001$; log DHEAS, adjusted $R^{2}=0.450, P<0.001$.

Variance inflation factors for all parameters are below 1.5 . 
Recent data have disclosed a high prevalence of HA among peripubertal adolescents with obesity, suggesting that such girls are indeed at risk for developing $\mathrm{PCOS}^{3)}$. The association between obesity and insulin resistance/hyperinsulinemia in childhood is already known ${ }^{24)}$ and even in prepuberty, obesity with hyperinsulinemia is a cardinal matter which was also confirmed in our study. The reported mechanism of development of PCOS from obesity is via insulin resistance and compensatory hyperinsulinemia, which augments androgen production and suppresses SHBG, thereby increasing androgen bioavailability ${ }^{3}$. And obesity itself increases androgen production $^{25)}$ and peripheral conversion of androstenedione to testosterone in adipose tissue ${ }^{26)}$. However, HA of OB peripubertal girls have conflicting results even in similar populations. McCartney et al. ${ }^{12)}$ reported that 8.8 fold and 2.2 fold higher mean FT level in OB than in non-OB Tanner I-II girls, respectively. While they could not find significant differences in overnight FT levels between $\mathrm{OB}$ and non-OB Tanner I-II girls in another study ${ }^{13)}$. It could be interpreted as that not only obesity or hyperinsulinemia but also other factors such as pubertal levels of gonadotropins are essentially included in the pathogenesis of HA, as it is indicated through other studies ${ }^{6}$. Insulin is able to decrease the hepatic production and secretion of $\mathrm{SHBG}^{27)}$. Moreover, insulin amplifies the stimulatory effect of LH on ovarian theca cells to increase androgen production ${ }^{17,19)}$, can increase adrenal responsiveness to adrenocorticotropin hormone for further androgen production $^{18)}$, and can cause pituitary hyperresponsiveness to gonadotropin-releasing hormone for increased LH secretion ${ }^{28)}$. The findings of this study, HA only in $\mathrm{OB}$ puberty not in $\mathrm{OB}$ prepuberty compared to NW subjects respectively, might be in the same line with the importance of the role of LH. FSH and insulin like growth factor-1 (IGF-1) also have been postulated to influence ovarian androgen production ${ }^{14)}$. Therefore, multifactorial mechanisms may be alleviate the impact of hyperinsulinemia or HOMR-IR on HA in our study.

As $\log$ LH was related to $\log$ DHEA in puberty subjects in our study, some studies reported that higher morning LH concentrations independently predict increased FT level better than fasting insulin, BMI $Z$-score, age, pubertal stage, and IGF- ${ }^{14)}$. However, Rosenfield and Bordini ${ }^{29)}$ mentioned that LH elevation appears to be secondary to HA and is absent in the most $\mathrm{OB}$ cases, so it does not seem to cause the hyperandrogenism although it may aggravate it. The pattern of LH secretion, amplitude and frequency, is variable according to Tanner stage, daytime or nighttime, and fatness ${ }^{6,13)}$. After puberty, LH levels show invert U-shape relative to BMI, though they are necessary for steroidogenesis ${ }^{29)}$; therefore, mechanism of HA especially related to LH secretion is not yet confirmed. In addition, although the association of obesity with early sexual maturation is well described ${ }^{30)}$, early signs of puberty (thelarche) do not generally reflect normal maturation of the hypothalamicpituitary-ovarian axis in $\mathrm{OB}$ girls ${ }^{31)}$. Thus, subjects with relatively immature gonadotropin-sex hormone axis might be included in $\mathrm{OB}$ pubertal group of this study. Although, LH:FSH ratios were not elevated in OB puberty group compared to NW puberty group in our study, women with PCOS have abnormally rapid LH pulses with reduced response to progesterone feedback, contributing to elevations in serum LH:FSH ratios ${ }^{32}$. Relative increase in LH leads to increased ovarian androgen synthesis and the resultant HA contributes to maintaining increased LH pulse frequency ${ }^{6}$. Thus when considering this vicious loop, the relationship between elevated progesterone levels and log FT or DHEAS in our study is understandable but whether progesterone level is the etiologic factor to HA is not sure.

Pubertal insulin resistance was confirmed in NW subjects. But plasma insulin levels or HOMA-IR values of OB prepuberty group were not lower than those of NW puberty group or $\mathrm{OB}$ puberty group. This was consistent with the other study which indicated that BMI was the predictor of insulin sensitivity changes during puberty ${ }^{33)}$. Interestingly, DHEAS levels were similar between OB prepuberty group and NW puberty group in our study. It may because hyperinsulinemia stimulates abnormal adrenal steroidogenesis ${ }^{34)}$, affecting DHEAS levels more directly than peripheral androgens. WHR is usually used as a visceral fatness index; WHR value above 0.86 is considered as having abdominal obesity, which is related to worse metabolic outcome than gluteal-femoral obesity $(\mathrm{WHR}<0.80)^{35)}$. However, the present study showed that WHR was not correlated to insulin or HOMA-IR, when age and BMI Z-score were controlled. Therefore, in a clinical setting, measuring waist and hip circumferences might not be beneficial when considering time and the effort.

There are some limitations in our study. First, only one timed sample was collected. All samples were collected in the early morning but secretory dynamics of gonadotropins and sex hormones is not clear and nocturnal change of LH secretions should be considered together ${ }^{13)}$. Second, bone age was not estimated. Bone age is advanced when a subject is OB through multiple mechanisms. For example, as reviewed above, insulin from adipose tissue related to obesity act on IGF-1 receptor. Therefore, height $Z$-score differences between NW and $\mathrm{OB}$ groups might be affected by bone age advancement especially in puberty. Third, although we excluded Tanner stage IV$\mathrm{V}$ subjects with progesterone levels above $2 \mathrm{ng} / \mathrm{mL}$, follicular or luteal phase should be identified for cases with mature menstrual cycle. Lastly, sample size of each group was small which could influence the level of statistical significance. In spite of these weaknesses, as Ibáñez et al. ${ }^{7}$ suggested, early recognition of girls at risk of developing hyperinsulinemic androgen excess is important for its prevention in childhood, and our study is worth as it included prepubertal OB girls even though they had not HA yet.

In conclusion, obesity per se was the most important factor for $\mathrm{HA}$ in $\mathrm{OB}$ pubertal girls who had significant $\mathrm{HA}$ and hyperinsulinemia. $\mathrm{OB}$ prepubertal girls did not show HA in the present study but they should be regularly monitored because they already had hyperinsulinemia. 


\section{Conflict of interest}

No potential conflict of interest relevant to this article was reported.

\section{Acknowledgments}

This study was supported by the Pediatric Research Fund of Korean Society of Pediatric Endocrinology (grant No. 2007-03).

\section{References}

1. Kim KE, Kim SH, Park S, Khang YH, Park MJ. Changes in prevalence of obesity and underweight among Korean children and adolescents: 1998-2008. Korean J Obes 2012;21:228-35.

2. Yang S, Hwang JS, Park HK, Lee HS, Kim HS, Kim EY, et al. Serum lipid concentrations, prevalence of dyslipidemia, and percentage eligible for pharmacological treatment of Korean children and adolescents; data from the Korea National Health and Nutrition Examination Survey IV (2007-2009). PLoS One 2012;7:e49253.

3. Anderson AD, Solorzano CM, McCartney CR. Childhood obesity and its impact on the development of adolescent PCOS. Semin Reprod Med 2014;32:202-13.

4. Vilmann LS, Thisted E, Baker JL, Holm JC. Development of obesity and polycystic ovary syndrome in adolescents. Horm Res Paediatr 2012;78:269-78.

5. Stanley T, Misra M. Polycystic ovary syndrome in obese adolescents. Curr Opin Endocrinol Diabetes Obes 2008;15:30-6.

6. Burt Solorzano CM, McCartney CR, Blank SK, Knudsen KL, Marshall JC. Hyperandrogenaemia in adolescent girls: origins of abnormal gonadotropin-releasing hormone secretion. BJOG 2010;117:143-9.

7. Ibáñez L, Ong KK, López-Bermejo A, Dunger DB, de Zegher F. Hyperinsulinaemic androgen excess in adolescent girls. Nat Rev Endocrinol 2014;10:499-508.

8. Azziz R, Carmina E, Dewailly D, Diamanti-Kandarakis E, Escobar-Morreale HF, Futterweit W, et al. Positions statement: criteria for defining polycystic ovary syndrome as a predominantly hyperandrogenic syndrome: an Androgen Excess Society guideline. J Clin Endocrinol Metab 2006;91:4237-45.

9. Pasquali R, Stener-Victorin E, Yildiz BO, Duleba AJ, Hoeger $\mathrm{K}$, Mason $\mathrm{H}$, et al. PCOS Forum: research in polycystic ovary syndrome today and tomorrow. Clin Endocrinol (Oxf) 2011;74:424-33.

10. Franks S. Adult polycystic ovary syndrome begins in childhood. Best Pract Res Clin Endocrinol Metab 2002;16:263-72.

11. McCartney CR, Prendergast KA, Chhabra S, Eagleson CA, Yoo R, Chang RJ, et al. The association of obesity and hyperandrogenemia during the pubertal transition in girls: obesity as a potential factor in the genesis of postpubertal hyperandrogenism. J Clin Endocrinol Metab 2006;91:171422.

12. McCartney CR, Blank SK, Prendergast KA, Chhabra $S$, Eagleson CA, Helm KD, et al. Obesity and sex steroid changes across puberty: evidence for marked hyperandrogenemia in pre- and early pubertal obese girls. J Clin Endocrinol Metab 2007;92:430-6.

13. McCartney CR, Prendergast KA, Blank SK, Helm KD, Chhabra S, Marshall JC. Maturation of luteinizing hormone (gonadotropin-releasing hormone) secretion across puberty: evidence for altered regulation in obese peripubertal girls. J Clin Endocrinol Metab 2009;94:56-66.

14. Knudsen KL, Blank SK, Burt Solorzano C, Patrie JT, Chang RJ, Caprio S, et al. Hyperandrogenemia in obese peripubertal girls: correlates and potential etiological determinants. Obesity (Silver Spring) 2010;18:2118-24.

15. Burt Solorzano CM, McCartney CR. Obesity and the pubertal transition in girls and boys. Reproduction 2010;140:399-410.

16. Reinehr T, de Sousa G, Roth CL, Andler W. Androgens before and after weight loss in obese children. J Clin Endocrinol Metab 2005;90:5588-95.

17. Cara JF, Rosenfield RL. Insulin-like growth factor I and insulin potentiate luteinizing hormone-induced androgen synthesis by rat ovarian thecal-interstitial cells. Endocrinology 1988;123:733-9.

18. Moghetti P, Castello R, Negri C, Tosi F, Spiazzi GG, Brun E, et al. Insulin infusion amplifies 17 alphahydroxycorticosteroid intermediates response to adrenocorticotropin in hyperandrogenic women: apparent relative impairment of 17,20-lyase activity. J Clin Endocrinol Metab 1996;81:881-6.

19. Nestler JE, Jakubowicz DJ, de Vargas AF, Brik C, Quintero $\mathrm{N}$, Medina F. Insulin stimulates testosterone biosynthesis by human thecal cells from women with polycystic ovary syndrome by activating its own receptor and using inositolglycan mediators as the signal transduction system. J Clin Endocrinol Metab 1998;83:2001-5.

20. Ng M, Fleming T, Robinson M, Thomson B, Graetz N, Margono C, et al. Global, regional, and national prevalence of overweight and obesity in children and adults during 1980-2013: a systematic analysis for the Global Burden of Disease Study 2013. Lancet 2014;384:766-81.

21. Korea Centers for Disease Control and Prevention, Division of Chronic Disease Surveillance, Committee for the Development of Growth Standard for Korean Children and Adolescents; Korean Pediatric Society, Committee for School Health and Public Health Statistics. 2007 Korean children and adolescents growth standard (commentary for the development of 2007 growth chart). Cheongju: Korea Centers for Disease Control and Prevention, Division of Chronic Disease Surveillance, 2007.

22. Vermeulen A, Verdonck L, Kaufman JM. A critical evaluation of simple methods for the estimation of free testosterone in serum. J Clin Endocrinol Metab 
1999;84:3666-72.

23. Matthews DR, Hosker JP, Rudenski AS, Naylor BA, Treacher DF, Turner RC. Homeostasis model assessment: insulin resistance and beta-cell function from fasting plasma glucose and insulin concentrations in man. Diabetologia 1985;28:412-9.

24. Strauss RS. Childhood obesity. Pediatr Clin North Am 2002;49:175-201.

25. Dieudonne MN, Pecquery R, Boumediene A, Leneveu MC, Giudicelli Y. Androgen receptors in human preadipocytes and adipocytes: regional specificities and regulation by sex steroids. Am J Physiol 1998;274(6 Pt 1):C1645-52.

26. Kershaw EE, Flier JS. Adipose tissue as an endocrine organ. J Clin Endocrinol Metab 2004;89:2548-56.

27. Pugeat M, Crave JC, Elmidani M, Nicolas MH, GaroscioCholet M, Lejeune $\mathrm{H}$, et al. Pathophysiology of sex hormone binding globulin (SHBG): relation to insulin. J Steroid Biochem Mol Biol 1991;40:841-9.

28. Soldani R, Cagnacci A, Yen SS. Insulin, insulin-like growth factor I (IGF-I) and IGF-II enhance basal and gonadotrophin-releasing hormone-stimulated luteinizing hormone release from rat anterior pituitary cells in vitro. Eur J Endocrinol 1994;131:641-5.

29. Rosenfield RL, Bordini B. Evidence that obesity and androgens have independent and opposing effects on gonadotropin production from puberty to maturity. Brain Res 2010;1364:186-97.

30. Wang Y. Is obesity associated with early sexual maturation? A comparison of the association in American boys versus girls. Pediatrics 2002;110:903-10.

31. Ahmed ML, Ong KK, Dunger DB. Childhood obesity and the timing of puberty. Trends Endocrinol Metab 2009;20:237-42.

32. Pastor CL, Griffin-Korf ML, Aloi JA, Evans WS, Marshall JC. Polycystic ovary syndrome: evidence for reduced sensitivity of the gonadotropin-releasing hormone pulse generator to inhibition by estradiol and progesterone. J Clin Endocrinol Metab 1998;83:582-90.

33. Travers SH, Jeffers BW, Bloch CA, Hill JO, Eckel RH. Gender and Tanner stage differences in body composition and insulin sensitivity in early pubertal children. J Clin Endocrinol Metab 1995;80:172-8.

34. Ibáñez L, Dimartino-Nardi J, Potau N, Saenger P. Premature adrenarche--normal variant or forerunner of adult disease? Endocr Rev 2000;21:671-96.

35. Wabitsch M, Hauner H, Heinze E, Böckmann A, Benz R, Mayer $\mathrm{H}$, et al. Body fat distribution and steroid hormone concentrations in obese adolescent girls before and after weight reduction. J Clin Endocrinol Metab 1995;80:346975 . 